\title{
EFFECT OF LEVENTIS FOUNDATION YOUTH AGRICULTURAL EMPOWERMENT PROGRAMME ON TRAINEES’ FOOD OUTPUT IN OSUN STATE, NIGERIA
}

\author{
K.A. ADELOYE ${ }^{1, *}$, A.O. AJAYI ${ }^{1}$, A.O. SOTOMI ${ }^{1}$ \\ *E-mail: kolaadeloye@oauife.edu.ng
}

Received: Apr. 06, 2020. Revised: June 15, 2020. Accepted: June 23, 2020. Published online: July 18, 2020

\begin{abstract}
The study assessed the effect of Leventis Foundation Youth Agricultural Empowerment Programme (LFYAEP) on trainees' food output in Osun State, Nigeria. A total of 248 extrainees of LFYAEP were selected and interviewed in the study area through a systematic random sampling technique using list of Leventis Foundation Agricultural School, Ilesa ex-trainees between the year 2010 and 2017 as sample frame. Data collected were presented using appropriate descriptive and inferential statistics. The mean age of the respondents was $30.0 \pm 6.2$ and their farming experience was 7.2 \pm 4.4 . About 74.7 and $77.6 \%$ got information about the empowerment through their community leaders and media respectively; also, they all participated to better their lot in life. In addition, there were high knowledge and skill proficiency in all the farm enterprises engaged in after the empowerment. Furthermore, the respondents recorded increased food output in all the farm enterprises engaged in after the empowerment. The findings revealed that at $p<0.05$, respondents' reasons for participation $\left(\chi^{2}=31.612\right)$ had significant
\end{abstract}

association with their food output. Furthermore, at $p<0.05$, farming experience $(r=0.483)$, age $(r=0.322)$, years of formal education $(r=0.153)$, knowledge possessed $(\mathrm{r}=0.148)$ and skill proficiency $(\mathrm{r}=0.221)$ of respondents had significant relationship with their food output. Finally, there was significant difference between food output before and after the empowerment $(\mathrm{F}=65.59)$. The study concludes that there was a significant improvement in the quantity and quality of food produced by the extrainees after the empowerment programme. It was recommended that similar empowerment should be put in place for all youth to enhance productivity.

Keywords: food security; farm management; ex-trainees.

\section{INTRODUCTION}

The youth, who are leaders of tomorrow, full of strengths should be encouraged to take to agricultural production. This could be achieved by

\footnotetext{
${ }^{1}$ Department of Agricultural Extension and Rural Development Obafemi Awolowo University, Ile-Ife, Nigeria
} 
empowering the youth in sustainable methods of agricultural production, which are devoid of drudgery, with early gratification and commensurable income. The emphasis is placed on youth empowerment for household food security in order to tap the advantage of their numerical strength.

Ajayi (2001) noted that the success of any youth targeted agricultural programme will depend on the interest of the youth, the prevailing norms and values of the people. Therefore, the government, the non-governmental organizations, the academics and other developmental agencies have a role to play in this matter. This was what prompted the establishment of Agricultural Empowerment by the Leventis Foundation.

\section{Leventis Foundation Agricultural Empowerment Programme (LFAEP)}

Leventis Foundation Youth Agricultural Empowerment Programme commenced in 1988 with the inauguration of two agricultural training schools one at Ilesa in Osun State and another at Dogondawa in Kaduna State. In 1990, another school was established in Panda, Kano State. In 2008, the foundation in collaboration with the government established additional two schools at Yaba in the Federal Capital Territory (FCT) and Tumu, in Gombe State. In 2009, another school was established in Ido-Ani, Ondo State in collaboration with the state government. The main objective of this programme is to train young
Nigerian small scale farmers in more efficient farm management practices, thereby encouraging them to take up farming as a profession. To meet this objective, the programme lay more emphasis on training for skill acquisition by devoting $80 \%$ of the training for practical while theory takes only $20 \%$ of the curriculum.

The programme is a one year intensive training (January to December) and each trainee is exposed to the following curriculum:

1. Crops and agroforestry: trainees are exposed to the production of arable crops such as maize (early and late), soybean, yam, pepper, oil palm seedling raising, cocoa seedling raising, beekeeping, snails rearing and grasscutter rearing.

2. Livestock and fisheries: trainees are exposed to various skills necessary in poultry, such as broiler production, pullet (egg-laying) rearing and cockerel production. Others are pig, rabbit aid fish production.

3. Agricultural engineering: trainees are taught on how to maintain farm tools, carry out construction and repairs of some farm buildings.

4. Rural Enterprise development: trainees are taught on how to keep farm records, process some farm products for storage such as fruits into fruit juice and jam, pepper into tomato without using any chemical preservative. To equip the trainees for off season income generating enterprises, the trainees are also trained on tie and dye textile production. 


\section{LEVENTIS FOUNDATION PROGRAMME ON TRAINEES' FOOD OUTPUT IN OSUN STATE, NIGERIA}

From the modest 24 all male enrolment in 1988, Leventis Foundation agricultural school Ilesa has trained 2,445 both male and female trainees up to 2017 (LFN, 2017). The general administration and supervision of these schools are the responsibility of the Head office of the foundation in Lagos.

The Foundation has been in operation to train and give micro credit assistance to interested youth to establish farms and value added enterprises for more than two decades, the impact of this organization needs to be studied. Adeloye (2004) and Alabi et al. (2017) in their separate studies on Leventis Foundation agricultural programme, evaluated the programme on the basis of training and infrastructural adequacy, but none of these studies made any reference to the change in knowledge, skill and attitude of the participants, which is significant in assessing food security and youth empowerment programme, like that of the Leventis Foundation, hence the focus of this work.

\section{Objective of the study}

The main objective of the study is to investigate the effect of Leventis Foundation youth agricultural empowerment programme on trainees' food output in Osun State, Nigeria. The specific objectives of the study are to: describe the socioeconomic characteristics of Leventis Foundation ex-trainees in the study area; determine ex-trainees level of knowledge and skills in farming enterprises; determine the output of the ex-trainees in quantity and quality before and after the empowerment programme in the study area.

\section{Hypotheses of the study}

There is no significant relationship between selected socioeconomic characteristics of Leventis Foundation ex-trainees and food output.

There is no significant relationship between the knowledge possessed, skill practiced by the extrainees and their food output.

There is no significant difference between the ex-trainees food output before and after the empowerment programme.

\section{MATERIALS AND METHODS}

The study area was Osun State Nigeria, created on $27^{\text {th }}$ August, 1991, situated in the Southwestern region of the country and lies within the co-ordinates of latitude $7^{\circ} 30^{\prime} \mathrm{N}$ of the equator and longitude $4^{\circ} 30^{\prime} \mathrm{E}$ of the Greenwich Meridian. The list of Leventis Foundation Agricultural School, Ilesa ex-trainees between the year 2010 and 2017 served as sample frame. A systematic random sampling technique with a random start at an interval of two was used to select thirty percent of ex-trainees from each selected year. A number of 248 respondents were selected for the exercise. Descriptive statistical techniques, such as frequency counts, percentages, mean, weighted mean scores pie chart and standard deviation, were used to describe the data. The relationship between the dependent variable (trainees food output) and the independent variables were determined by the use of chi-square analysis, Pearson 
product moment correlation (PPMC) and analysis of variance (ANOVA).

\section{Measurement of variable Dependent variable}

The dependent variable was conceptualized as the food output of trainees of Leventis Foundation youth agricultural empowerment programme. The food output of the ex-trainees after the empowerment programme in various agricultural enterprises, such as crop, poultry, piggery, fishery and beekeeping, were given in kilogramme for crop and fishery, number for poultry and piggery and liter for bee keeping. These outputs were then converted to monetary value, summation of which was used as the food output of these ex-trainees per annum.

\section{Ex-trainee's knowledge level}

This was measured by using a knowledge checklist on selected management practices in crop production, pig production, poultry production and beekeeping. Score 1 for each of the knowledge statement answered correctly and 0 for wrongly answered. Maximum of 11 points for crop, 9 points for poultry, 7 points for pig production, and 7 points for beekeeping. Summation of all respondents score was calculated and the grand mean was used to categorize the respondents, those with score above the grand mean as high and those below the grand mean as low.

\section{Ex-trainee's skill proficiency}

This was measured by listing skills in crop production, poultry production, pig production and bee- keeping. The extrainees were asked to indicate their proficiency level on each skill on 5 scale level and were scored as follows: very much $=4$, much $=3$, average $=2$, little $=1$ and nothing $=0$. The score was used to categorise the ex - trainees skill proficiency on each enterprise as high, medium and low using mean score +/ standard deviation.

\section{RESULTS AND DISCUSSION}

\section{Socioeconomic characteristics \\ of ex-trainees}

Results in Table 1 reveals that the mean age of the respondents was 30.0 , with standard deviation of 6.2. This implies that the respondents comprised people of active minds and bodies, which might be versatile in making use of knowledge and skills acquires through the programme. Majority (93.1\%) of them was male, this results indicates that the outreaches were gender sensitive. The table also shows that the respondents interviewed had an average farming experience of 7.2 , with standard deviation of 4.4. Since very few $(0.4 \%)$ were not having years of formal education less than 10 ; it implies that majority were literate and it is in conformity with LFN (2017) that reported that the minimum academic requirement for the programme was Junior Secondary School Certificate. In addition, the result indicates that information about the programme in the study area was mainly through media $(75.6 \%)$, community leaders $(74.7 \%)$ and personnel of the programme $(71.4 \%)$. Furthermore, the respondents participated in the programme to better their lot in life; this is a departure from previous reasons for participating in development outreaches (mere interest and leisure), as reported by Olujide and Adeogun 


\section{LEVENTIS FOUNDATION PROGRAMME ON TRAINEES' FOOD OUTPUT IN OSUN STATE, NIGERIA}

(2006). Majority (72.6) of the and sale, with average farm size of respondents produce for consumption $1.6 \pm 0.3$ hectares.

Table 1 - Socio-economic characteristics of respondents $(n=248)$

\begin{tabular}{lll}
\hline \multicolumn{2}{l}{ Variables } & \multicolumn{2}{l}{ Percentages } & \\
\hline Age (years) & 8.1 & Mean $=30.0$ \\
\hline Below 24 & 44.7 & Standard deviation $=6.2$ \\
\hline $24-31$ & 47.2 & \\
\hline Above 32 & & \\
\hline Farming experience (years) & 46.8 & Mean $=7.2$ \\
\hline Below 6 & 42.0 & Standard deviation $=4.4$ \\
\hline $6-12$ & 14.2 & \\
\hline Above 12 & & \\
\hline Sex & 93.1 & \\
\hline Male & 6.9 & Mean $=12.5$ \\
\hline Female & & Standard deviation $=1.4$ \\
\hline Years of formal education & 0.4 & \\
\hline Below 10 & 84.3 & \\
\hline $10-12$ & 15.3 & \\
\hline Above 12 & 71.4 & \\
\hline *Sources of information about the programme \\
\hline programme's personnel & 59.8 & \\
\hline Neighbours/ Friends & 74.7 & \\
\hline Community leaders & 75.6 & \\
\hline Media & 75.0 & \\
\hline *Reasons for participation in the programme & \\
\hline To make ends meet & 60.4 & \\
\hline Personal interest & 25.0 & \\
\hline For leisure & 100.0 & \\
\hline To better my lot in life & 24.8 & \\
\hline Farm size (hectares) & 51.2 & \\
\hline Below 5 & 24.0 & \\
\hline 5-10 & & \\
\hline Above 10 & & \\
\hline
\end{tabular}

Source: Field survey, 2018; *Multiple responses

\section{Ex-trainees' knowledge on farm enterprises}

Result in Table 2 further revealed that majority $(91 \%)$ of the ex-trainees have high knowledge in crop production management practices, it also show that majority $(90.7 \%)$ of the ex-trainees have high knowledge level in poultry production. In addition, it shows that majority (87.5) of the ex-trainees exhibit high knowledge level in pig production. Furthermore, it show that majority of the ex-trainees $(70.6 \%)$ possessed high knowledge level in bee keeping, while $29.4 \%$ have low knowledge level. The high knowledge level in all the farm enterprise may be attributed to the prior training that these ex-trainees have been exposed to. This finding corroborates that of Alabi et al. (2017), who reported that 
ex-trainees of LFAEP ranked highest crop production as the leading

enterprise they were exposed to during their training.

Table 2 - Distribution of the ex-trainees' knowledge on farm enterprises by categories $(n=248)$

\begin{tabular}{|c|c|c|c|c|}
\hline Category & Scores & Frequence & $\%$ & Mean \\
\hline \multicolumn{5}{|l|}{ Crop production } \\
\hline High knowledge & $>10.8$ & 226 & 91 & \\
\hline Low knowledge & $<10.8$ & 22 & 9 & 10.8 \\
\hline \multicolumn{5}{|l|}{ Poultry } \\
\hline High knowledge & $>8.8$ & 225 & 90.7 & \\
\hline Low knowledge & $<8.8$ & 23 & 9.3 & 8.8 \\
\hline \multicolumn{5}{|l|}{ Pig production } \\
\hline High knowledge & $>6.8$ & 217 & 87.5 & \\
\hline Low knowledge & $<6.8$ & 31 & 12.5 & 6.8 \\
\hline \multicolumn{5}{|l|}{ Beekeeping } \\
\hline High knowledge & $>6.6$ & 175 & 70.6 & \\
\hline Low knowledge & $<6.6$ & 73 & 29.4 & 6.6 \\
\hline
\end{tabular}

Source: Field survey, 2018

Ex-trainees by skill proficiency level on enterprises

Result in Table 3 revealed that many $(55.2 \%)$ have medium skill proficiency level in crop production, also many $(46.8 \%)$ of the ex-trainees have high skill proficiency in poultry production; however, majority ( $84.7 \%)$ of the ex-trainees have medium skill in pig production, and many $(47.2 \%)$ of the ex-trainees have medium skill in bee keeping enterprise.

This findings is in tandem with that of Sotomi (2012), which reported that the Leventis Foundation School of Agriculture ex-trainees have high skill proficiency in crop and pig production.

\section{Quantity of food output before and} after empowerment programme

Result in Table 4 revealed that the mean value of maize was $\$ 19,192.00$ and $\$ 163,904.03$ per annum before and after the empowerment programme, respectively. Crops, such as plantain and pineapple, were not planted by the ex-trainees before the empowerment programme, but have appreciable mean values of $\$ 192,631.58$ and $\$ 135,806.45$ per annum, respectively, after the empowerment programme.

It also revealed $11,244.96$ and $\mathrm{N} 154,744.15$ per annum as mean values for broiler production before and after the empowerment programme, respectively. There was an appreciable improvement in pullet production, which was not practiced before the empowerment programme, but recorded 62, 903.27 per annum, as mean value after the empowerment. In addition, it shows the mean value of pig as $\$ 5,584.68$ before the empowerment programme and $\$ 162,903.27$ per annum after the empowerment programme. 


\section{LEVENTIS FOUNDATION PROGRAMME ON TRAINEES' FOOD OUTPUT IN OSUN STATE, NIGERIA}

Furthermore, it shows the mean value of fish production to be nothing and $\$ 162,701.71$ per annum before and after the empowerment programme, respectively.

The implication of this result was that the respondents have

increase in food output in all the enterprises engaged in after the empowerment; this might be connected with knowledge and skill proficiencies exposed to during their trainings.

Table 3 - Distribution of the ex-trainees categorization by skill proficiency level on enterprises $(n=28)$

\begin{tabular}{llllll}
\hline Categories & Scores & Frequency & Percentage & Mean & S.D \\
\hline Crop & \multicolumn{5}{l}{} \\
\hline Low & $<28.4$ & 39 & 15.6 & & \\
\hline Medium & $28.4-36.6$ & 137 & 55.2 & 32.5 & 4.1 \\
\hline High & $>36.6$ & 72 & 29.2 & & \\
\hline Poultry & & & & & \\
\hline Low & $<13.8$ & 67 & 27.0 & & \\
\hline Medium & $13.8-24.7$ & 65 & 26.2 & 19.1 & 5.6 \\
\hline High & $>24.7$ & 116 & 46.8 & & \\
\hline Pig & & & & & \\
\hline Low & $<7.0$ & 18 & 7.2 & & 5.1 \\
\hline Medium & $7.0-17.2$ & 210 & 84.7 & 12.1 & 5.1 \\
\hline High & $>17.2$ & 20 & 8.1 & & \\
\hline Beekeeping & & & & & \\
\hline Low & $<12.1$ & 41 & 16.5 & & \\
\hline Medium & $12.1-26.1$ & 117 & 47.2 & 19.1 & 7.0 \\
\hline High & $>26.1$ & 90 & 36.3 & & \\
\hline
\end{tabular}

Source: Field survey, 2018

Quality of food output before and after empowerment programme

Result in Table 5 revealed that many $(38.7 \%)$ of the respondents sold their maize crop fresh, while only $5.2 \%$ processed the crop before the empowerment. Majority (76.6\%) of the respondents sold their maize fresh, while $14.9 \%$ processed the crop after the empowerment programme. From the interaction on the field it was revealed that fresh maize brings higher returns on investment in some localities, hence the preference for fresh sales. It also revealed that all the poultry products were sold life before and after the empowerment programme. The implication of this is that the ex-trainees are not adding value to their poultry products. In addition, it revealed that all respondents sold their pig life before and after the empowerment programme. It however revealed that none of the respondents was involved in fish production before the empowerment, and all the ex-trainees involved in fish production after the empowerment programme sell their products fresh. Furthermore, it shows that all ex-trainees producing honey sold their products unpackaged before 
the empowerment programme. their products before sale after the However, $19.8 \%$ sell their honey unpackaged, while $13.3 \%$ packaged empowerment product.

Table 4 - Distribution of the ex-trainees by quantity of food output before and after the empowerment programme $(n=248)$

\begin{tabular}{lll}
\hline \multirow{2}{*}{ Enterprise } & \multicolumn{2}{c}{ Mean value of quantity output (\$) } \\
\cline { 2 - 3 } Crop & \multicolumn{3}{c}{ Before empowerment } & After empowerment \\
\hline Maize & $19,192.00$ & $163,904.03$ \\
\hline Cassava & $18,932.25$ & $121,330.64$ \\
\hline Yam & $114,102.82$ & $161,552.42$ \\
\hline Vegetables & $11,483.87$ & $97,492.98$ \\
\hline Cocoa & $13,121.46$ & $144,737.90$ \\
\hline Oil palm & $13,180.62$ & $164,681.45$ \\
\hline Plantain & 0.000 & $192,631.58$ \\
\hline Pineapple & 0.000 & $135,806.45$ \\
\hline Poultry & & \\
\hline Broiler & $11,244.96$ & $154,744.15$ \\
\hline Pullet & 0.000 & $162,903.27$ \\
\hline Cockerel & $11,260.08$ & $126,157.26$ \\
\hline Local chicken & $1,500.00$ & $11,705.00$ \\
\hline Turkey & $11,132.39$ & $67,161.29$ \\
\hline Duck & 11.120 .17 & $77,288.31$ \\
\hline Piggery & $15,584.68$ & $165,221.77$ \\
\hline Fishery & 0.000 & 162.701 .61 \\
\hline Beekeeping (honey) & $11,135.08$ & $75,040.32$ \\
\hline
\end{tabular}

Source: Field survey, 2018; Note: Naira value was used ( $\$ 1=\$ 359.61)$.

Food output and socioeconomic characteristics of LFYAEP ex-trainees

Result in Table 6 reveals that at 0.05 level of significance, sex $\left(\chi^{2}=\right.$ $32.851)$ and reasons for participating in LFYAEP $\left(\chi^{2}=31.612\right)$ had significant association with food output of the ex-trainees.

Result in Table 7 reveals that at 0.05 level of significance, LFYAEP ex-trainees farming experience $(\mathrm{r}=0.483)$, farm size $(\mathrm{r}=0.501)$, age $(\mathrm{r}=0.322)$, years of formal education $(\mathrm{r}=0.153)$, knowledge possessed $(\mathrm{r}=0.148)$ and skill proficiency $(r=0.221)$ had significant relationship with their food output.

\section{Relationship between ex-trainees food output before and after LFYAEP}

In order to test this hypothesis, analysis of variance (ANOVA) was used on food output of the ex-trainees before the empowerment and their food output after the empowerment programme. $\mathrm{F}$ value $=65.59$ at $\mathrm{p} \leq 0.05$ revealed that there was a significant difference between the extrainees food output before the empowerment programme and the food output after the empowerment programme. 
Table 5 - Distribution of the ex-trainees by quality of food output before and after the empowerment programme $(n=28)$

\begin{tabular}{lllll}
\hline *Enterprise & \multicolumn{2}{l}{ Before empowerment } & \multicolumn{2}{l}{ After empowerment } \\
\hline Crop & Fresh F (\%) & Processed F (\%) & Fresh F (\%) & Processed F (\%) \\
\hline Maize & $98(38.7)$ & $14(5.6)$ & $190(76.6)$ & $37(14.9)$ \\
\hline Cassava & $74(29.8)$ & $5(2.0)$ & $80(32.3$ & $0(0.0)$ \\
\hline Yam & $26(10.5)$ & $0(0.0)$ & $26(10.5)$ & $0(0.0)$ \\
\hline Vegetables & $8(3.2)$ & $0(0.0)$ & $47(19.6)$ & $0(0.0)$ \\
\hline Cocoa & $4(1.6)$ & $0(0.0)$ & $12(4.4)$ & $0(0.0)$ \\
\hline Oil palm & $2(0.5)$ & $0(0.0)$ & $10(4.0)$ & $3(1.2)$ \\
\hline Plantain & $0(0.0)$ & $0(0.0)$ & $11(4.4)$ & $1(0.4)$ \\
\hline Pineapple & $0(0.0)$ & $0(0.0)$ & $6(2.4)$ & $0(0.0)$ \\
\hline Poultry & Life F (\%) & Processed F (\%) & Life F (\%) & Processed F (\%) \\
\hline Broiler & $5(2.0)$ & $0(0.0)$ & $129(52.0)$ & $0(0.0)$ \\
\hline Pullet & $0(0.0)$ & $0(0.0)$ & $113(45.6)$ & $0(0.0)$ \\
\hline Cockerel & $5(2.0)$ & $0(0.0)$ & $142(57.7)$ & $0(0.0)$ \\
\hline Local chicken & $33(13.3)$ & $0(0.0)$ & $30(12.4)$ & $0(0.0)$ \\
\hline Turkey & $2(0.6)$ & $0(0.0)$ & $2(0.6)$ & $0(0.0)$ \\
\hline Duck & $2(0.2)$ & $0(0.0)$ & $1(0.4)$ & $0(0.0)$ \\
\hline Pig & $15(8.8)$ & $0(0.0)$ & $83(33.5)$ & $0(0.0)$ \\
\hline Fish & $0(0.0)$ & $0(0.0)$ & $10(4.0)$ & $0(0.0)$ \\
\hline Beekeeping & Unpacked & Packed & Unpacked & Packed \\
\hline Honey & $2(0.6)$ & $0(0.0)$ & $49(19.8)$ & $33(13.3)$ \\
\hline
\end{tabular}

Source: Field survey, 2018; *Multiple responses

Table 6 - Relationship between selected socioeconomic characteristics of LFYAEP ex-trainees and their food output

\begin{tabular}{lrll}
\hline Variables & $\mathbf{x}^{2}$ Value & DF & p-value \\
\hline Sex & 32.851 & 2 & $0.003^{*}$ \\
\hline Sources of information about the progeamme & 4.370 & 6 & 0.635 \\
\hline Reason for participating in the programme & 31.612 & 4 & $0.001^{*}$ \\
\hline
\end{tabular}

Source: Calculated from field survey, 2018; * $p \leq 0.05$; DF- Degree of freedom

Table 7 - Relationship between other socioeconomic characteristics of LFYAEP ex-trainees and their food output

\begin{tabular}{lll}
\hline Variables & $\begin{array}{l}\text { Correlation } \\
\text { coefficient }(\mathbf{r})\end{array}$ & $\begin{array}{l}\text { Coefficient of } \\
\text { determination }\left(\mathbf{r}^{2}\right)\end{array}$ \\
\hline Age & $0.322^{*}$ & 0.1037 \\
\hline Farming experience & $0.483^{*}$ & 0.2530 \\
\hline Years of formal education & $0.153^{*}$ & 0.0234 \\
\hline Farm size & $0.501^{*}$ & 0.2510 \\
\hline Knowledge possessed & $0.148^{*}$ & 0.0219 \\
\hline Skill practiced & $0.221^{*}$ & 0.0488 \\
\hline
\end{tabular}

Source: Calculated from field survey, $2018 ;{ }^{*} p \leq 0.05$ 


\section{CONCLUSION AND RECOMMENDATIONS}

Based on the findings of the study, it was concluded that LFYAEP ex-trainees possessed high knowledge and skills in many agricultural enterprises embarked upon after the empowerment programme; also, there was a significant improvement in the quantity and quality of food produced by the ex-trainees after the empowerment programme.

From the study, it was found that a very few female ex-trainees engaged in farming business; therefore, it is recommended that agricultural enterprises which are female oriented, such as marketing and processing, should be given attention to in the training.

Many of the ex-trainees are practicing on less than 1 ha of farmland, as a result of nonavailability of farmland; therefore, efforts should be made to collaborate with relevant government agencies that will assist these youths in land acquisition for farming activities.

There is need to intensify efforts on product processing and packaging in order to add value to farm products so as to maximize profit on these products.

Since improvement was noticed in food output in quantity, quality and variety after the empowerment programme, therefore, Leventis Foundation Youth Agricultural Empowerment Programme is recommended for all youth both practicing and intended ones to enhance productivity.

\section{REFERENCES}

Adeloye K.A. (2004). An evaluation of the role of non-governmental organisations (NGOs) in agricultural development in Osun State. Case study of Leventis Foundation Nigeria School of Agriculture llesa, Osun State, Nigeria. Unpublished B. Agric. Thesis in Department of Agricultural Extension and Rural Development, Obafemi Awolowo University, Ile-Ife, Nigeria.

Ajayi A. A. (2001). Participation of rural children in farming activities in Oyo State in Nigeria. Unpublished Postgraduate Thesis Ph.D. in Department of Agricultural Extension and Rural Development, Obafemi Awolowo University, lle-Ife, Nigeria.

Alabi, O. S., Ajayi, A. O. \& Akinwale, E. O. (2017). Agricultural production practices of ex-trainees of Leventis Foundation School of Agriculture, Ilesa, Osun State. Moor J.Agric. Res., 18: 12-21.

LFN (2007). Leventis Foundation (Nigeria) Ltd/Gte, Cardillac press, pp. 5-214.

Olujide, M.G. \& Adeogun, S.O. (2006): Assessment of cocoa growers' farm management practices in Ondo State, Nigeria.

Olujide, M.G. \& Adeogun, S.O. (2006). Assessment of cocoa growers' farm management practices in Ondo State, Nigeria. Span.J.Agric.Res., 4(2): 173-179.

Sotomi, A.O. (2012). Effect of Leventis Foundation Youth Agricultural Empowerment Programme on trainees' food output in Osun State, Nigeria. Unpublished Master of Science Thesis in Department of Agricultural Extension and Rural Development, Ile-Ife, Nigeria. 